\title{
Reviews and Syntheses: optical sampling of the flux tower footprint
}

\author{
J. A. Gamon \\ Department of Earth \& Atmospheric Sciences, and Department of Biological Sciences, \\ University of Alberta, Edmonton, Alberta, Canada
}

Correspondence to: J. A. Gamon (jgamon@gmail.com)

Received: 27 January 2015 - Published in Biogeosciences Discuss.: 30 March 2015

Accepted: 14 July 2015 - Published: 30 July 2015

\begin{abstract}
The purpose of this review is to address the reasons and methods for conducting optical remote sensing within the flux tower footprint. Fundamental principles and conclusions gleaned from over 2 decades of proximal remote sensing at flux tower sites are reviewed. The organizing framework used here is the light-use efficiency (LUE) model, both because it is widely used, and because it provides a useful theoretical construct for integrating optical remote sensing with flux measurements. Multiple ways of driving this model, ranging from meteorological measurements to remote sensing, have emerged in recent years, making it a convenient conceptual framework for comparative experimental studies. New interpretations of established optical sampling methods, including the photochemical reflectance index (PRI) and solar-induced chlorophyll fluorescence (SIF), are discussed within the context of the LUE model. Multiscale analysis across temporal and spatial axes is a central theme because such scaling can provide links between ecophysiological mechanisms detectable at the level of individual organisms and broad patterns emerging at larger scales, enabling evaluation of emergent properties and extrapolation to the flux footprint and beyond. Proper analysis of the sampling scale requires an awareness of sampling context that is often essential to the proper interpretation of optical signals. Additionally, the concept of optical types, vegetation exhibiting contrasting optical behavior in time and space, is explored as a way to frame our understanding of the controls on surface-atmosphere fluxes. Complementary normalized difference vegetation index (NDVI) and PRI patterns across ecosystems are offered as an example of this hypothesis, with the LUE model and light-response curve providing an integrating framework. I conclude that experimental approaches allowing systematic exploration of plant optical behavior in the context of the flux tower network provides
\end{abstract}

a unique way to improve our understanding of environmental constraints and ecophysiological function. In addition to an enhanced mechanistic understanding of ecosystem processes, this integration of remote sensing with flux measurements offers many rich opportunities for upscaling, satellite validation, and informing practical management objectives ranging from assessing ecosystem health and productivity to quantifying biospheric carbon sequestration.

\section{Introduction}

The global flux tower network has greatly expanded our understanding of the exchange of mass and energy between terrestrial ecosystems and the atmosphere (Baldocchi et al., 2001). Emerging from a long history of research in the micrometeorological community, eddy covariance has increasingly been integrated with ecophysiological perspectives to become an essential tool for understanding terrestrial ecosystem photosynthesis and productivity. Examples of this integration include eddy covariance studies that apply the concept of light response curves to the analysis of whole ecosystem fluxes (Wofsy et al., 1993; Goulden et al., 1997). Originally derived from the ecophysiological literature using steady-state gas exchange (Björkman, 1981), photosynthetic response curves enable powerful functional analyses of the physiological controls on gas exchange (von Caemmerer and Farquhar, 1981; Long and Bernacchi, 2003). When applied to surface-atmosphere fluxes, response curves can reveal insights into the environmental and biological controls on these fluxes. They can also be used for partitioning net flux into gross (photosynthetic) and respiratory fluxes (Reichstein et al., 2012). The light-response curve also provides a powerful theoretical construct for integrating optical and 
flux data within the framework of the light-use efficiency (LUE) model, allowing a deeper, physiological examination of ecosystem function than possible from monitoring fluxes or optical signals alone.

Like eddy covariance, remote sensing emerged from a physical sciences background, and its history has often focused on mapping and monitoring broad vegetation types or a few key biophysical parameters (e.g., leaf area index (LAI), biomass, or $\left.f_{\mathrm{PAR}}\right)$ rather than providing a functional understanding of underlying ecosystem physiological responses. In part, this limitation derives from the relatively coarse scale of most global Earth observations. Observations of largescale phenology through broad spatial and temporal patterns of greenness (normalized difference vegetation index (NDVI); Tucker et al., 1985), and the redefinition of terrestrial biomes through their spatially and temporally dynamic NDVI properties (Defries and Townshend, 1994), are classic studies that illustrate the power of remote sensing to map vegetation patterns over continental regions and yearly timescales. The development of the MODIS net primary production (NPP) products (Running et al., 2004) have moved beyond depictions of spatial and temporal patterns of vegetation to a more functional description of vegetation dynamics and productivity, but still at relatively coarse spatial and temporal scales that can be difficult to directly relate to flux tower sites. Biome-scale comparisons of aggregated optical properties to yearly integrated NPP (Goward et al., 1985) and gross primary production (GPP, Frankenberg et al., 2011) demonstrate the parallel abilities of optical remote sensing and flux measurements to characterize broad-scale patterns of ecosystem-atmosphere exchange and ecosystem production, even if the mechanistic details operating at finer temporal and spatial scales remain obscure. Our current challenge is to fill in those details, and proximal remote sensing within the flux tower footprint provides an important means to accomplish this.

In the past, remote sensing and flux measurements have often been seen as fundamentally different disciplines, and the integration of these methods to address ecosystematmosphere fluxes is a relatively new phenomenon. An important stimulus of this transition to an integrated approach has been NASA's field campaigns, particularly FIFE (Sellers et al., 1992b) and BOREAS (Sellers et al., 1997). These large studies began to integrate eddy covariance and remote sensing in a systematic way, and exposed entire generations of scientists to the kind of interdisciplinary thinking needed for ecosystem physiology and global ecology. Since that time, the advent of new tools - principally improved field spectrometers and sampling platforms - have enabled more detailed optical studies of the flux tower footprint. The emergence of optical sampling networks such as SpecNet (Gamon et al., 2006b, 2010), EuroSpec (this issue), and the Phenocam network (Richardson, 2009) have drawn attention to the need for more systematic integration of proximal remote sensing within the flux tower network.
In this review, I will argue that direct integration of remote sensing with flux measurements within the context of the global flux tower network improves our understanding of both fluxes and remote sensing. This integration offers greater insights into the underlying controls on biosphericatmospheric fluxes than possible with either method alone. While optical sampling is readily scalable, a key focus will be on proximal remote sensing explicitly designed to match the sampling scale of flux measurements as a means of understanding functional processes. Proximal sampling can also be readily linked to conventional remote sensing, providing critical validation (e.g., "ground truthing") and extrapolation of fine-scale measurements to larger regions ("upscaling"). While optical methods will be the primary focus, other methods (e.g., LIDAR, thermal, microwave, or acoustic) can also be applied to a wide range of ecological questions within the flux footprint. A primary conceptual framework will be the LUE model, in part due to the rich history of this approach, but also because many potential parameterizations of this model remain largely unexplored, providing rich opportunities for new advances. When properly applied, proximal remote sensing offers many prospects for a deeper, physiological examination of whole ecosystem function, and can be seen as an emerging ecophysiological frontier.

\section{Sampling context}

A well-designed proximal remote sensing campaign must consider sampling context, including the scale of biological responses in temporal and spatial dimensions. Attention to the temporal and spatial context is essential because optical and flux instrumentation, and the biological processes they detect, operate with different time constants over different spatial scales (Figs. 1 and 2). The context also includes the angular response of illumination and the measured signals. Attention to the spectral (wavelength) domain is also needed as optical instruments and the biological phenomena they measure can be very particular when it comes to spectral responses.

We can illustrate the spectral-spatial-temporal domain by defining the realm of optical sampling using ecosystem photosynthetic carbon uptake and its underlying biological controls as an example. Plants possess a myriad of ways to adjust the receipt and distribution of light energy, all of which can be detected optically (Fig. 1). These photosynthetic regulatory processes operate over a wide range of scales. At fine spatial and temporal scales, leaves adjust light energy distribution via energy dissipation mechanisms, including chlorophyll fluorescence (red text in Fig. 1), which responds to illumination in milliseconds and relaxes to steady-state levels over seconds to minutes (Jones, 2013). At slightly longer timescales (seconds to hours), non-radiative energy dissipation via the xanthophyll cycle (Demmig et al., 1987) provides further means of adjusting energy distribution (left side of 


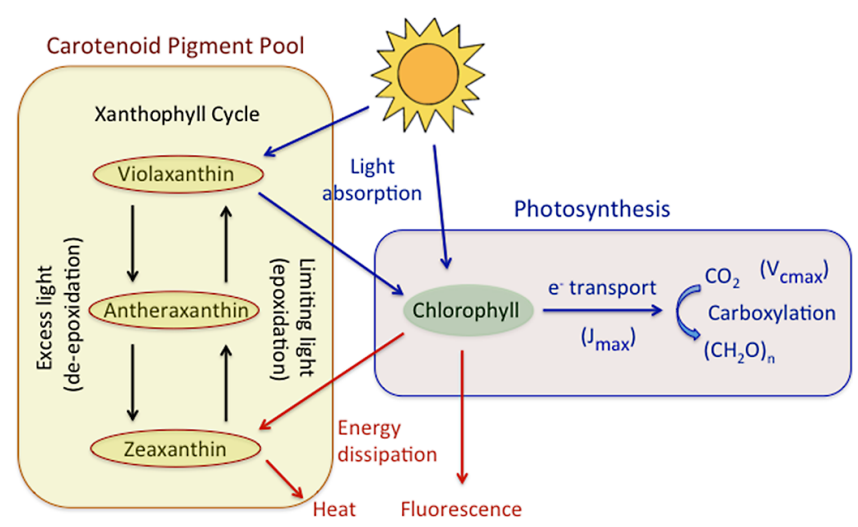

Figure 1. Distribution of absorbed radiation within a leaf, showing processes of productive photosynthesis (blue text and arrows), energy dissipation (red text and arrows), regulatory processes associated with the xanthophyll cycle (black text and arrows within box on left), and carotenoid and chlorophyll pigment pools, all of which can be assessed with optical sampling, but at different temporal, spatial and spectral scales, as discussed in the text.

Fig. 1), and these changes can be monitored via fluorescence and spectral reflectance (Gamon et al., 1990, 1997; Peñuelas et al., 1995). Critical biochemical aspects of photosynthetic regulation (e.g., Rubisco activation) occur over similarly short timescales, and this biochemical capacity, illustrated as carboxylation capacity $\left(V_{\mathrm{cmax}}\right)$ and electron transport capacity $\left(J_{\max }\right)$ in Fig. 1 , can be assessed with optical methods (Serbin et al., 2012). In parallel to these photochemical and biochemical regulatory processes, leaf structure, ultrastructure, and pigmentation are adjusted over minutes (in the case of chloroplast or rapid leaf movement) to days or weeks (in the case of pigment pool sizes and leaf area index) (Björkman and Demmig-Adams, 1994). These adjustments affect leaf and canopy light absorption (blue text in Fig. 1), and can be detected via spectral transmittance (Brugnoli and Björkman, 1992) or reflectance (Zygielbaum et al., 2012; Wong and Gamon, 2015a).

At the scale of the flux tower footprint, vegetation's capacity to absorb light based on the amount of green canopy material determines its potential photosynthetic rate and net primary productivity. This capacity varies with canopy and stand structure, often expressed as green leaf area index, leaf angle distribution, or percent cover, which can be measured as the fraction of PAR irradiance absorbed $\left(f_{\mathrm{APAR}}\right)$ using a number of vegetation reflectance indices, most notably the NDVI (Gamon et al., 1995; Running et al., 2004).

Each of these optically detectable processes influences photosynthetic rates, and thus NPP or net ecosystem exchange (NEE), and can be best detected over a particular range of temporal, spatial, and spectral scales (Fig. 2). Depending upon whether we are monitoring rapid physiological adjustments or slower structural changes, a combination of optical sampling methods (irradiance, absorption, re-

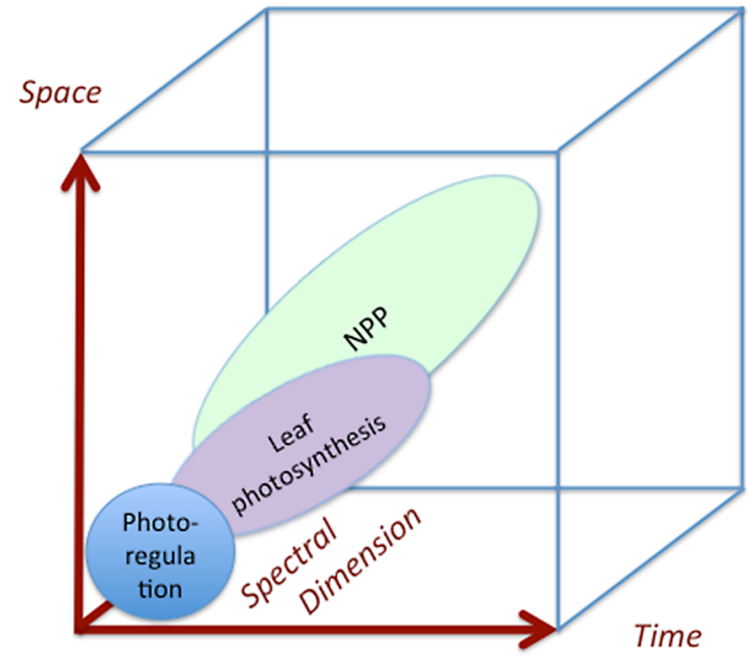

Figure 2. The sampling domain defined by time, space, and spectral space ( $z$ dimension) axes, illustrating how the optical sampling scale varies with the process being measured. The time and space axes are typically log scales (Osmond and Chow, 1988). The spectral or wavelength axis (represented as the $z$ dimension), will also vary with the type and purpose of optical sampling. Similarly, the appropriate degree of data aggregation in temporal, spatial, and spectral domains will also vary with the purpose at hand.

flectance, or fluorescence) might be deployed, and the optimal sampling scale and method of interpretation will vary. When judiciously applied within the flux footprint, these optical methods provide a powerful range of tools for an improved understanding of the physiological and structural controls on fluxes at different scales, independently of the flux measurements themselves. When used in combination across sampling scales, they also facilitate exploration of emergent properties, allowing us to determine which underlying controls can become obscured, and which ones emerge as critical to the whole-ecosystem performance (sensu Michaletz et al., 2014).

\section{The light-use efficiency model as a unifying concept}

When estimating ecosystem photosynthesis or production from remote sensing, a common approach is to use the lightuse efficiency (LUE) model in one of its many forms. Derived from the seminal work of Monteith (1977) on crops, the original LUE model states that dry matter yield can be expressed as a function of the amount of intercepted solar radiation (IPAR, typically expressed as photosynthetically active radiation), and the efficiency $(\varepsilon)$ with which that radiation is converted to biomass.

Yield $=\operatorname{IPAR} \times \varepsilon$

Monteith's LUE formulation provided an elegant conceptual model that has been further developed, and extensively 
tested for many of the world's terrestrial ecosystems. Over the years, the original LUE model has expanded to become a family of models with slightly different formulations, parameterizations, and implications for flux-optical analyses. While similar in concept, these variations differ in practice, often leading to strikingly different conclusions (Gitelson and Gamon, 2015). To consider these implications as they apply to this discussion, it is necessary to briefly examine some of the key features of these newer models.

In the remote sensing literature, a common formulation of the LUE model is to express GPP as a function of absorbed radiation and the efficiency $(\varepsilon)$ with which that absorbed radiation is converted to fixed carbon.

$\mathrm{GPP}=\mathrm{APAR} \times \varepsilon$

Absorbed radiation (APAR) can be further defined as the product of incident photosynthetic photon flux density (PPFD, or PAR irradiance, often called "PAR" in the remote sensing literature) and the fraction of incident PPFD absorbed by photosynthetic canopy materials $\left(f_{\mathrm{APAR}}\right)$. The strength of this model derives in part from the strong relationship between optical vegetation indices, particularly the NDVI and the fraction of radiation absorbed by green canopy materials $\left(f_{\text {APAR }}\right)$, which provides a metric of photosynthetic capacity (Kumar and Monteith, 1981; Sellers, 1987; Hall et al., 1992; Gamon et al., 1995; Running et al., 2004). Because it is often the dominant variable in Eq. (2), APAR is fundamental to the determination of photosynthetic rate or GPP with this model. While simple in concept, several factors, including canopy structure, soil or other "background" effects (Hall et al., 1992), view angle and solar illumination (discussed below), can all influence the NDVI signal and the accuracy of APAR estimation. Consequently, evaluation of these factors is critical to estimating whole-stand photosynthesis from optical sampling.

\subsection{Assessing efficiency $(\varepsilon)$}

The basic LUE concept is easily illustrated using plots of hypothetical leaf- and stand-level light responses (Fig. 3). At the leaf scale, the initial slope represents the photon (quantum) yield, the intrinsic LUE measured with leaf gas exchange (Fig. 3a). For healthy plants, there is a strong convergence of photon yield values across species sharing similar photosynthetic pathways (Björkman, 1981), contributing to the concept of an idealized, maximal LUE. At the stand scale, the light response of unstressed canopies is often more linear due to the patterns of light absorption with canopy depth (Norman and Arkebauer, 1991) and LUE is the slope of this APAR-photosynthesis relationship (Fig. 3b). Consequently, an optically derived APAR can be compared to ecosystem carbon gain (GEP or GEE) from gas exchange or eddy covariance, allowing the calculation of whole-ecosystem LUE as the resulting slope (e.g., Huemmrich et al., 2010). If this slope is constant, LUE can be readily inferred, providing a
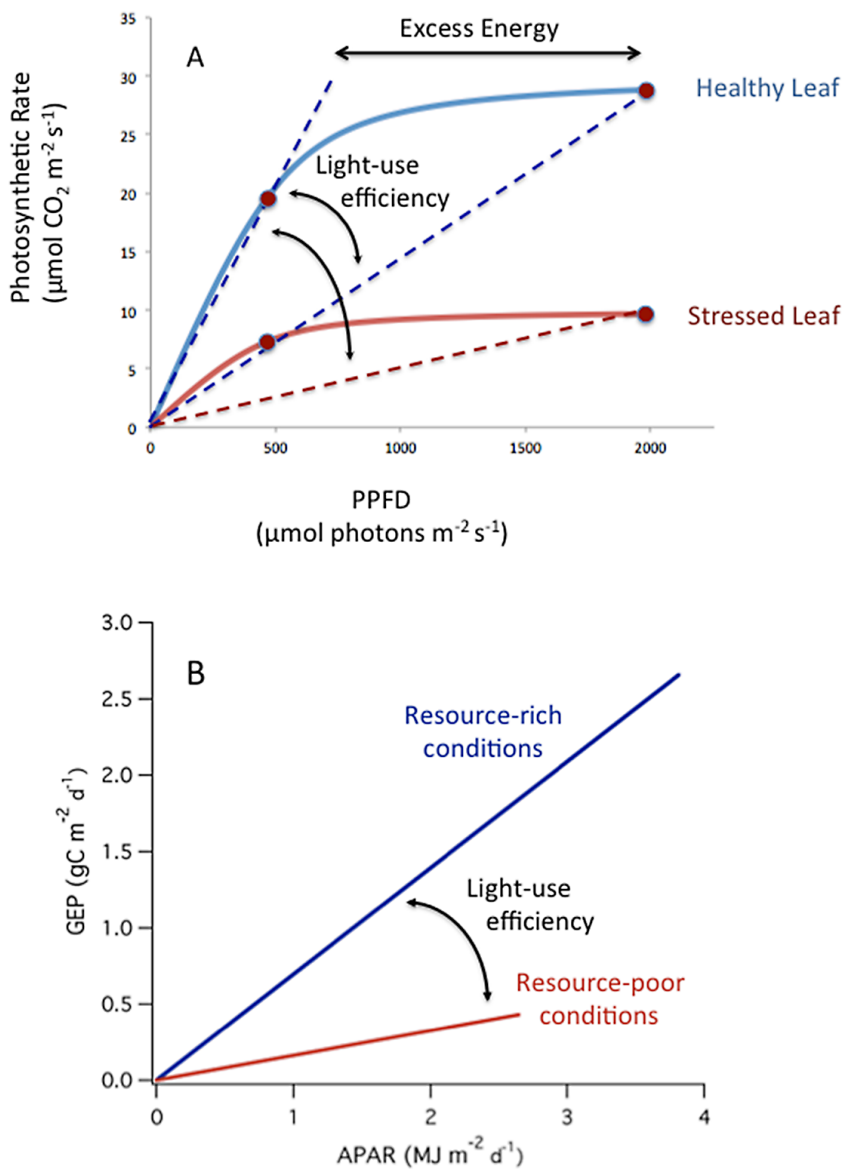

Figure 3. (a) Modeled photosynthetic light-response curves (rectangular hyperbola) for healthy and stressed leaves, illustrating the decline in light-use efficiency (LUE), typically termed photon (or quantum) yield. (b) Stand-level light-response curves of gross ecosystem production (GEP) for different vegetation types having different moisture regimes, LUEs, and contrasting optical properties. (a) Modified from Björkman and Demmig-Adams (1994). (b) Modified from Huemmrich et al. (2010).

key input for the LUE model, and vegetation can be functionally categorized according to its LUE response. If the slope is variable, then we must reconsider this assumption, as further discussed below.

The light-response curve provides a potent framework for analyzing physiological responses and for deciding how to best integrate optical and flux measurements. In this analysis, because APAR reflects the amount of light absorbed by green canopy structure, it provides key information on the structural control on fluxes associated with such factors as green canopy cover and LAI, and depicts the maximum potential photosynthesis determined by light absorption. By contrast, the slope (efficiency, $\varepsilon$ ) represents how much of that photosynthetic potential is actually realized due to variations in environmental conditions and physiological performance. In this way, a changing slope can provide additional information 
on the degree of physiological control associated with photosynthetic adjustment and down-regulation under varying environmental conditions. This distinction between structural and physiological controls is somewhat artificial; in nature, structural and physiological factors interact in interesting and complex ways. Nevertheless, it provides a useful conceptual framework for analyzing ecosystem behavior and determining how best to parameterize the LUE model.

A strength of the LUE model is that APAR can be readily assessed from optical remote sensing. A bigger challenge than APAR assessment lies in determining the efficiency $(\varepsilon)$ term in the LUE model, in part because it can vary with vegetation type and environmental conditions (Garbulsky et al., 2010). In some cases, for a given vegetation type and time frame, $\varepsilon$ can be treated as a constant, greatly simplifying the LUE model (Monteith, 1977; Ruimy et al., 1994). This view is analogous to the observation that all unstressed leaves of a particular type $\left(\mathrm{C}_{3}\right.$ or $\left.\mathrm{C}_{4}\right)$ tend towards a common photon yield (LUE expressed at the leaf level), representing optimal conversion efficiency (Björkman, 1981). However, nature often grossly violates the assumption of a constant LUE, and recent studies have emphasized the large temporal variation in $\varepsilon$, particularly during conditions of chronic stress (Garbulsky et al., 2010). In these cases, environmental factors including temperature, moisture, and nutrients cause the efficiency term to vary on a variety of timescales, leading to large errors in LUE model estimates that assume a fixed $\varepsilon$. In extreme cases, such as evergreen conifers that undergo winter downregulation of photosynthesis (Wong and Gamon, 2015b), $\varepsilon$ can reach zero during cold periods and become the dominant term in the LUE model (Eq. 2). For any given ecosystem, the shape of the light response curve (Fig. 3) can tell us which assumption about $\varepsilon$ is most appropriate, illustrating the value of an integrated approach that combines optical and flux sampling.

To capture these $\varepsilon$ dynamics, some common expressions of the LUE model partition the efficiency term into a fixed component that represents the optimal efficiency for a given vegetation type, and a variable component that depicts the effect of temperature or water stress on reducing that efficiency:

$\varepsilon=\varepsilon_{\max } \times m(T) \times m(\mathrm{VPD})$,

where $\varepsilon_{\max }$ represents the maximal efficiency for a given vegetation type, $m(T)$ is a scalar that reduces efficiency due to temperature extremes, and $m(\mathrm{VPD})$ is a scalar that reduces efficiency due to drought, often expressed as vapor pressure deficit (VPD) (Heinsch et al., 2006). This formulation can be used to derive efficiency from meteorological measurements, which can be interpolated from weather stations, or derived directly from flux tower sensors (Running et al., 2004; Heinsch et al., 2006). Not surprisingly, local inputs sometimes yield better results than interpolated inputs (Running et al., 2004), illustrating the challenge of merging disparate data sets collected at different locations for different purposes. Often, accurate meteorological data is simply not available for a given region, limiting the accuracy of the meteorologically based approach.

\subsection{Optical Assessment of Efficiency}

In part to circumvent this challenge of mismatched and missing meteorological data, many studies have explored remote sensing to more directly assess $\varepsilon$. Reflectance, fluorescence, and thermal methods can all be relevant due to their ability to detect different stresses. One example is provided by the photochemical reflectance index (PRI), which was original defined as a measure of xanthophyll cycle pigment conversion, and thus provides an optical assessment of $\varepsilon$ dynamics, similar to chlorophyll fluorescence yield $\left(\Delta \mathrm{F} / \mathrm{Fm}^{\prime}\right)$ over a diurnal timescale (Gamon et al., 1992, 1997; Peñuelas et al., 1995). Unlike $\Delta \mathrm{F} / \mathrm{Fm}^{\prime}$, which is limited to proximal measurement scales due to the requirement of a saturating light pulse, PRI relies on reflected radiation and can be applied over a range of scales, but this also adds challenges to the interpretation. Over longer timescales, or when comparing different species or vegetation types, a primary cause of PRI variation is the adjustments in pigment pool sizes, notably chlorophyll carotenoid ratios, that strongly influence the PRI wavelengths (Garrity et al., 2011; Wong and Gamon, 2015a). Several recent studies have explored these pool size effects and related them to photosynthetic activity, with promising results. For evergreen species, PRI often varies strongly with season (Wong and Gamon, 2015a, b) or with canopy position and light environment (Gamon and Berry, 2012) primarily due to changing chlorophyll : carotenoid levels. This pigment ratio declines during periods of chronic stress, providing a readily detectable optical index of seasonally changing photosynthetic activity and $\varepsilon$, with further diurnal modulation in PRI driven by the xanthophyll cycle (Wong and Gamon, 2015a, b). These observations are consistent with studies illustrating the utility of pigments as optical indicators of photosynthetic activity and GPP (Sims and Gamon, 2002; Peng et al., 2011), and are contributing to a changing view of how we might best utilize PRI in the assessment of photosynthetic activity.

Much of the confusion in the recent PRI literature arises from the fact that multiple factors drive variation in PRI over different temporal scales (Barton and North, 2001), and relatively few studies have fully considered sampling context or attempted to distinguish these multiple causes. The importance of the temporal context for PRI assessment is illustrated in Fig. 4, showing short-term facultative changes due to xanthophyll cycle activity dominated by long-term constitutive pool size effects varying with chronic stress (e.g., due to drought or temperature extremes). The interaction of these two temporally changing PRI components yields complex spatial patterns of PRI within the flux footprint due to the complex, dynamic light regimes within a stand (Hilker et 


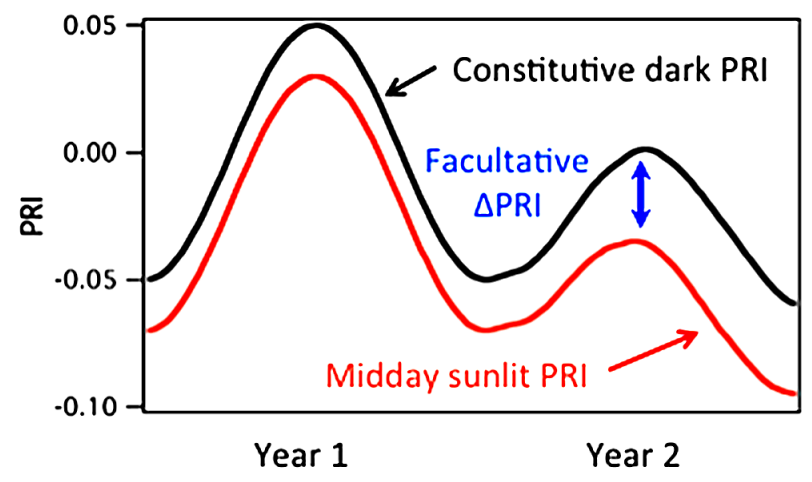

Figure 4. Illustration of constitutive (pigment pool size) and facultative (xanthophyll cycle) effects on PRI time series, representing two annual cycles of PRI for evergreen vegetation. In this case, the dominant cause of PRI variation is the constitutive adjustment in chlorophyll : carotenoid ratios across seasons, with less variation due to the diurnal xanthophyll cycle operation ( $\triangle \mathrm{PRI})$, a facultative process that further modulates light energy distribution (Fig. 1). In year two, chronic stress (e.g., drought) causes reduction in the constitutive component (dark-state PRI) along with additional adjustments of the facultative component $(\triangle \mathrm{PRI})$. Adapted from Sims et al., 2006 and Wong and Gamon (2015a).

al., 2008; Middleton et al., 2009). These light patterns cause PRI to vary with canopy depth (Gamon et al., 2001, 2005) and aspect (Gamon and Bond, 2013) with varying contributions from facultative and constitutive components (Gamon and Berry, 2012). Direct assessment of photosynthetic activity and $\varepsilon$ with PRI remains an area of ongoing research, requiring a careful consideration of sampling context affecting these PRI components. Some sampling methods allow separation of PRI into its facultative xanthophyll cycle and constitutive pigment pool components. These methods typically distinguish a baseline, dark-state (constitutive) PRI from a $\triangle \mathrm{PRI}$, the difference between the dark-state PRI and a midday illuminated value (Gamon and Surfus, 1999; Sims et al., 2006; Hilker et al., 2008, 2010; Gamon and Berry, 2012; Soudani et al., 2014), often improving our understanding of $\varepsilon$ and related physiological controls on photosynthesis.

Further studies are needed to clarify the contributions of the facultative and constitutive PRI components to photosynthetic regulation over temporal and spatial scales relevant to whole-ecosystem fluxes. Over the past 2 decades, the functional significance of gradual changes in carotenoid pigment pools has received far less attention than the shortterm regulation of the xanthophyll cycle, despite the clear importance of pigment pool sizes as indicators of vegetation stress responses (Sims and Gamon, 2002). Neither the slow nor the rapid pigment responses have yet been fully addressed in mechanistic models of photosynthesis, which tend to focus more on biochemical processes (e.g., $V_{\text {cmax }}$, Serbin et al., 2012). Thus, there is potential to develop more integrated photosynthesis models that link the full range of pigment responses and concurrent optical signals (including

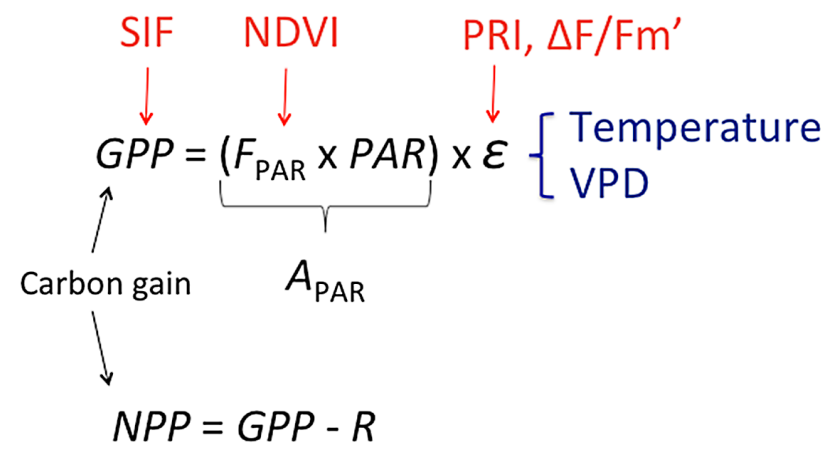

Figure 5. Representation of the LUE model (Eq. 2), showing optical measurements useful for model parameterization and validation (red text), including solar-induced fluorescence, the NDVI, the $\mathrm{PRI}$, and fluorescence yield $\left(\Delta \mathrm{F} / \mathrm{Fm}^{\prime}\right)$. Alternatively, efficiency $(\varepsilon)$ can be addressed using meteorological data (temperature and vapor pressure deficit) according to Eq. (3), or can be addressed with thermal remote sensing and modeling methods (Anderson et al., 2008; Schull et al., 2015). To most directly compare with eddy covariance, which measures NEE (analogous to NPP), additional modeling, or partitioning into gross ecosystem production (GEP, analogous to gross primary production, GPP) and respiration $(R)$, is needed.

both reflectance and fluorescence) to dynamic photosynthetic activity. Recent findings of a functional link between PRI, carotenoid biochemistry, and vegetation isoprenoid emission (Peñuelas et al., 2013) indicate that PRI and carotenoid biochemistry can offer new insights into the controls on other trace gas fluxes in addition to $\mathrm{CO}_{2}$. Other concurrent sampling methods, including thermal methods that provide independent assessment of chronic stresses, can add even greater insight into flux controls by integrating evapotranspiration and energy balance with the LUE approach (Anderson et al., 2008; Schull et al., 2015). Consequently, there is ample opportunity for further exploration and clarification of diurnal and seasonal flux controls by integrating indices such as NDVI and PRI with other sampling methods (e.g., irradiance, fluorescence, and thermal measurements), and flux towers properly instrumented with optical sensors offer ideal opportunities for further investigation of this topic. A full understanding will require a combination of empirical experiments and modeling studies at multiple scales. To be successful, this effort will require careful attention to standardized protocols that address sampling context, as further defined below.

\subsection{Comparing LUE model parameterizations}

Several common parameterizations of the LUE model are illustrated in Fig. 5, showing optical inputs in red and meteorological inputs in blue. Relatively few studies consider more than one model parameterization, and those that do are often limited to a few of the many possible models (Zhang et al., 2015). Consequently, the "best" parameterization remains an open question and may depend upon the tools available and 
the particular context or question of interest, with different investigators pursuing different approaches. A key opportunity lies in comparing these different approaches to each other and across sites within the context of the flux tower network. As discussed below, it is likely that any single parameterization will not apply equally well across all ecosystems, biomes, or seasons due to operational issues and contrasting controls on physiology and structure, but this is also an open question.

\subsection{Solar-induced fluorescence}

For years, studies have noted a close association between solar-induced chlorophyll fluorescence (SIF) and photosynthetic activity (Carter et al., 1990). Recent studies, mostly from spaceborne platforms, have demonstrated a strong link between GPP and SIF (Frankenberg et al., 2011; Joiner et al., 2011, 2014). The technical breakthrough of recent SIF studies arose from the recognition that atmospheric absorption bands (e.g., the Fraunhofer lines) contain a small fluorescence signal that can be detected with the appropriate narrow-band instruments, allowing quantification of this small signal against a larger background of solar radiation (Damm et al., 2010; Meroni et al., 2009). Some of these studies are the accidental consequence of satellites designed for other purposes, so the fluorescence measurements have not been optimized in terms of the signal-to-noise ratio. Because this fluorescence signal in these satellite instruments is relatively weak, data must be either aggregated over large regions, annual timescales, or both, providing coarse, biome-scale estimates instead of site-based measurements. This aggregation has demonstrated remarkable coarse-scale agreement between fluorescence and GPP for most biomes (Frankenberg et al., 2011; Joiner et al., 2011, 2014), but necessarily obscures the influence of fine-scale regulatory mechanisms, which have yet to be fully addressed in most SIF studies.

Despite the novelty of these recent spaceborne applications, basic fluorescence theory has been understood for decades (see reviews by Meroni et al., 2009; Porcar-Castell et al., 2014), and the chlorophyll fluorescence signal is known to be affected by both the amount of illuminated chlorophyll (related to APAR) and the degree of photosynthetic down-regulation (related to non-photochemical quenching and $\varepsilon$ ) (Porcar-Castell et al., 2014; van der Tol et al., 2014). As a demonstration of the latter point, fluorescence yield $\left(\Delta \mathrm{F} / \mathrm{Fm}^{\prime}\right)$, typically derived using the pulse-amplitude modulated (PAM) method, provides an excellent means of assessing $(\varepsilon)$, closely matching short-term PRI dynamics, but far less scalable, since the PAM technique requires a saturating light pulse, restricting the measurements to proximal measurements (Gamon et al., 1997). Thus, it is plausible that SIF, because it is readily scalable and sensitive to both terms of the LUE model, can provide an optical metric that often correlates with realized rates of photosynthesis or GPP, bypassing the need for independent assessment of the LUE model terms (Fig. 5).

Since several of the recent observations of SIF have been at a coarse biome scale, more work is needed to confirm the SIF-GPP hypothesis, and to compare this method against other established optical methods over a range of temporal and spatial scales, with proper consideration of sampling context. Ideally, these studies would combine empirical and modeling studies and integrate optical sampling with photosynthetic measurements in the context of the threedimensional vegetation structure and dynamic canopy light regime (e.g., van der Tol et al., 2009, 2014). As of this writing, few off-the-shelf commercial instruments have sufficient narrow bandwidth, signal-to-noise ratio, and stability to extract a reliable fluorescence signal needed for such work. Consequently, there is a need for better instrumentation, and several research groups are actively developing and testing improved instruments for proximal SIF application. Currently, there is ample opportunity for testing the SIF fluorescence approach using the flux tower network and LUE model as a validation framework. Ideally, such experiments would include not only fluxes, but also other optical measurements (e.g., irradiance and NDVI and PRI) to independently and simultaneously assess the LUE model components illustrated in Fig. 5.

\section{Sampling considerations: a question of scale}

When considering the operational scale of ecosystem flux measurements using eddy covariance, the challenges of integration with optical sampling across scales becomes clear. Many eddy covariance systems collect data at 10 to $20 \mathrm{~Hz}$, and report summary data on half-hourly time steps (Burba and Anderson, 2010). When expressing net primary production (NPP), yearly aggregated carbon uptake is a common expression. Aggregating flux data over such large temporal scales misses many of the fine-scale regulatory processes described above, each of which can provide a partial understanding of the environmental constraints and physiological responses that can contribute to the overall controls of photosynthesis or productivity. Thus, a key challenge in comparing optical and flux measurements lies in careful consideration of scale, and development of the most appropriate methods for sampling and subsequent data aggregation in the temporal or spatial dimensions. Because of the complexity of stand light regimes, angular scale (e.g., sun angle and view angle) can be considered an additional sampling dimension. The spectral scale represents an additional sampling dimension that must be carefully matched to the question at hand. Key examples of scaling issues as applied to optical measurements are further discussed below. 


\subsection{Spatial dimension}

Due to the inherent variability of the flux tower footprint (Vesala et al., 2008), matching the full sampling region with optical sampling is a challenging task. From a practical perspective, it is difficult to obtain a meaningful, spatially representative sampling of the footprint without disturbing the vegetation or flux measurements themselves. While tractable in short-statured vegetation, this becomes far more difficult for vegetation exceeding 2-3 $\mathrm{m}$ in height. A brief discussion of instrumentation is warranted here. The choice of method and its proper application depends to a large extent on the particular sampling objective. To follow basic physiological processes, high-frequency leaf- or canopy-scale sampling is often used, and automated methods may be necessary. For fully characterizing the flux tower footprint, fine-grained sampling (ideally $1 \mathrm{~m}^{2}$ on a daily time step or finer) is often optimal. Most publicly available satellite data are typically too coarse-grained to provide this level of spatially detailed footprint monitoring. Commercial satellite options, some of which sample at fine spatial scales, tend to be cost prohibitive for routine applications. Airborne sampling can provide a flexible platform to help fill this need, but typically at a high cost. Consequently, to sample in the footprint, many new applications of field spectrometers have been developed (Fig. 6). Most of these methods are either limited in height (Fig. 6a, c) or in spatial replication (Fig. 6b), making full footprint sampling difficult. The advent of inexpensive drones that can carry small spectrometers (Fig. 6d) now offer improved optical coverage of the entire flux footprint, as technical and legal issues (Elias, 2012) become resolved. Alternatively, new automated, portable sensors, including twoband NDVI or PRI sensors (Eklundh et al., 2011; Harris et al., 2014; Gamon et al., 2015) allow greater flexibility in sampling, particularly in the time domain. Wireless sensor networks enable improved spatial coverage, but at added cost and complexity. Affordable, image-based methods, including multi-band cameras, portable imaging spectrometers, and webcams (Fig. 6b), are now becoming widely available (e.g., Richardson et al., 2009) and offer the interpretive power of imagery, but with additional analytical challenges resulting from ill-defined sampling geometry, which can create difficulties when trying to conduct cross-site or multi-season analyses. Due to the disparate, evolving nature of these different sampling methods, a key informatics challenge lies in the integration of data collected, often with distinct proprietary formats, over contrasting scales. Flux tower sites provide ideal test beds for developing integrated approaches for multiple sensors, and this could help in evaluating scaling effects and emergent properties.

\subsection{Angular dimension}

Because vegetation optical signals have a strong angledependency, consideration and normalization of sampling

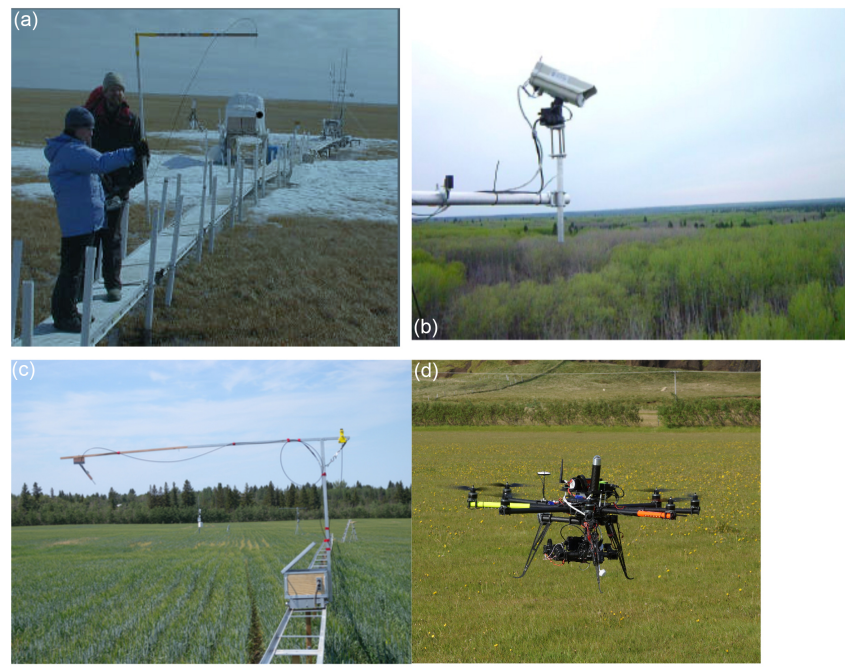

Figure 6. Optical sampling methods applied to spatially extensive sampling within flux tower footprint. (a) Hand sampling along a boardwalk leading to a flux tower, (b) automated sampling with an automated spectrometer ("AMSPEC") and webcam mounted on a flux tower (adapted from Hilker et al., 2010; Hilker et al., 2011), (c) automated sampling with a tram, a motorized cart on a track, and (d) airborne sampling with an octocopter drone (photo courtesy Richard Streeter and Alasdair Mac Arthur). (a-c) depict the "UniSpec DC" (PP Systems, Amesbury MA), a dual detector instrument that can be configured for manual or automatic sampling from a variety of platforms. The "Cinestar 8" drone (d) carries a dual field-of-view VNIR "Piccolo" spectrometer (developed by Alasdair MacArthur NERC FSF), comprised of a spectral detector (USB 2000, Ocean Optics, Dunedin FL, USA) with a shuttered, bifurcated fiber providing alternate upward and downward sampling. Note that all methods correct for changing sky conditions, either by simultaneous $(\mathbf{a}-\mathbf{c})$, or alternating $(\mathbf{d})$ radiance and irradiance sampling, allowing expanded sampling in both space and time to match the scale of eddy covariance measurements.

geometry is needed if standard products are to be generated and compared (Barton and North, 2001; Hilker et al., 2008, 2011). Traditionally, optical remote sensing emphasizes the nadir (vertical) view, in part because it provides a standard that can be readily replicated and measured from above. Multi-angle measurements can help provide a deeper functional understanding of vegetation optical signals relevant to fluxes (Hilker et al., 2011), largely because vegetation physiology and resulting patterns of reflected radiation are so responsive to illumination. This can become especially relevant when evaluating diurnal responses or comparing measurements across latitudes, seasons, or contrasting stand structures (Hilker et al., 2010). Vegetation physiology and structure both affect the measured optical signals, which are also strongly influenced by sun angle or sky conditions (Barton and North, 2001). The interplay between these factors can be complex, varying with wavelength and time and vegetation type, creating an overdetermined situation that makes it 


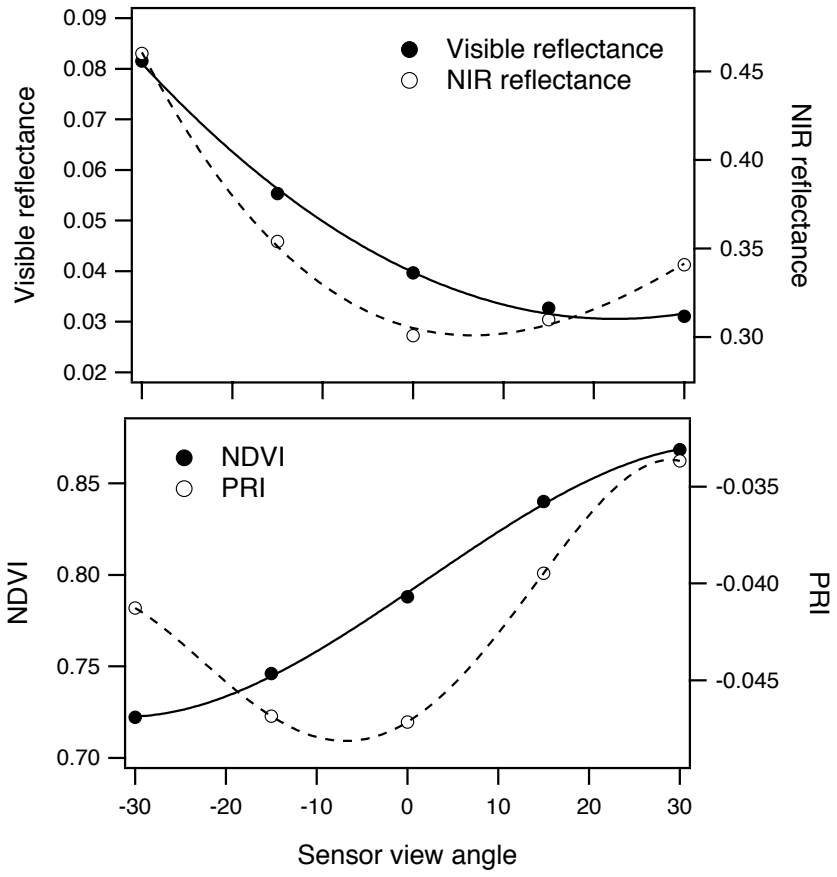

Figure 7. Angular response of several optical vegetation indices, including visible or near-infrared (NIR) reflectance (top panel), the NDVI, and the PRI (bottom panel). Data from a barley (Hordeum vulgare L.) field in Edmonton, Alberta (Canada), at solar noon on 24 July 2009 using a UniSpec DC (PP Systems, Amesbury, MA, USA) mounted on a tram system (Fig. 6c). Each point is a mean of 52-74 samples collected along a 50m track (running E-W) within $30 \mathrm{~min}$ of solar noon. Sensor view angle was measured in the solar principal plane. The backscatter direction (looking away from the midday sun) is indicated by negative sensor view angles.

hard to resolve the underlying physiological and structural components influencing optical signals related to fluxes. The strong effects of view angle alone can yield contradictory conclusions regarding the interpretation of physiological signals such as PRI (Drolet et al., 2008; Goerner et al., 2009; Guarini et al., 2014).

The significant effect of view angle on albedo, NDVI and PRI is illustrated for a barley (Hordeum vulgare L.) stand in Fig. 7, demonstrating distinct patterns for each spectral region and index, and indicating a stronger midday PRI decline towards the backscatter direction. Note that each index and wavelength region has a unique angular response, and this would be expected to vary with vegetation structure, latitude, time of year, time of day, and sky conditions. For this barley stand, NDVI and PRI both decline towards the backscatter direction (the "hotspot," indicated by high albedo), but in different ways. Due to this complexity, it is often more effective to sample richly in time and space at multiple view angles, allowing the generation of response curves that can be represented as continuous functions (Fig. 7). This approach allows normalization for view angle, enabling systematic isolation of the effect of individual factors on the resulting optical signals, sometimes greatly improving the relationship between optical signals and fluxes (Hilker et al., 2008, 2011), and improving agreement across sites with different vegetation types (Hilker et al., 2010). Alternatively, diurnal measurements can be used to model vegetation reflectance responses to sun angle, also normalizing for confounding effects, similarly improving the relationship between vegetation indices and fluxes (Sims et al., 2006). Clearly, an optical sampling campaign must be sensitive to stand structure and illumination, and the "best" method for addressing these angular effects remains an active area of investigation.

\subsection{Temporal dimension}

New developments in technology have greatly expanded our ability to measure optical signals over a range of temporal scales, allowing continuous optical sampling within the flux tower footprint (Huemmrich et al., 1999; Hilker et al., 2007; Gamon et al., 2010; Eklundh et al., 2011). Traditionally, optical remote sensing has been limited to clear-sky conditions. In many of the world's biomes, frequent cloud cover restricts sampling to few clear-sky options, making representative sampling of the time domain difficult. New proximal methods are changing this by sampling under the atmosphere using instruments that correct for changing sky conditions, typically by normalizing between paired sensors comparing simultaneous upwelling and downwelling radiation (Fig. 6). By reducing the requirement for clear sky conditions, these methods greatly expand the ability to collect optical data across time, better matching the continuous data collected by eddy covariance, and providing a continuous optical phenology that often closely relates to seasonal patterns of photosynthetic activity (Huemmrich et al., 1999; Gamon et al., 2010). They also reveal impacts of sky conditions on vegetation optical responses, providing a useful analogue to eddy covariance studies directly demonstrating effects of cloud cover on ecosystem carbon uptake. These eddy covariance studies have sometimes reported higher photosynthetic rates or light-use efficiencies for vegetation stands under clouds relative to clear skies due to deeper light penetration under diffuse skies (Goulden et al., 1997; Knohl and Baldocchi, 2008). This seemingly counterintuitive conclusion can be further explained by optical measurements that demonstrate deeper light penetration under diffuse skies (Gamon et al., 2006a). Since we now have automated methods that sample continuously under all sky conditions, scale-appropriate optical measurements can now be used to provide an independent explanation and validation of flux responses to changing sky conditions. Because of the methods of temporal aggregation used for eddy covariance data, similar temporal aggregation of optical data may also be needed, particularly when integrating optical data with fluxes. 


\subsection{Spectral dimension}

For practical reasons, this review has emphasized a small number of possible optical sampling methods and bands illustrative of key aspects of the LUE model. However, the realm of optical sampling spans a wide spectral range of the solar spectrum, from roughly $300 \mathrm{~nm}$ (in the near-UV) to $2500 \mathrm{~nm}$ (the short-wave infrared). A full consideration of all wavebands, indices, and other spectroscopic methods is beyond the scope of this review, and the reader is referred to a number of recent publications for a more comprehensive exploration of the spectral dimension (e.g., Ustin et al., 2004, 2009; Sims and Gamon 2002). However, a few salient points are summarized here. Depending upon the specific sampling goal, some methods use relatively few, discrete bands to assess particular features, while others may utilize the full spectral range, yielding a seemingly infinite number of sampling possibilities. Similarly, analytical approaches can range from specific targeted approaches using a few optimal formulations (e.g., Sims and Gamon, 2002, 2003) to more openended statistical methods to discover which bands or formulations can yield the best result for a given purpose or context (e.g., Serbin et al., 2012). Proper attention to waveband definition (both spectral position and bandwidth) is essential, particularly for detecting specific physiological features (e.g., pigments, water content, or chlorophyll fluorescence). Many narrow-band indices such as PRI are notoriously sensitive to formulation, requiring users and metadata to specify the exact band definitions used, and this may vary slightly with instrument manufacturer (Castro et al., 2006), or even among instruments from the same manufacturer (Harris et al., 2015). Greater attention to standardization of instruments, calibration procedures, and field methods is clearly needed. Given the multiplicity of brands, calibration methods, and field protocols in use, improved attention to band definitions in reporting data and metadata is also needed, particularly if we are to compare results across instruments or studies (Gamon et al., 2010; Balzarolo et al., 2011). With the increased availability of full-spectral instruments leading to increased exploration of the spectral domain (Ustin et al., 2004, 2005; Campbell et al., 2013), the topic of the spectral dimension will undoubtedly require further attention.

\section{Vegetation optical types}

The variation in optical behavior can reveal contrasting vegetation light absorption (APAR), light-use efficiency $(\varepsilon$ ), and other functional differences, particularly when combined with flux measurements, reflecting differing environmental and evolutionary constraints. This introduces the hypothesis of vegetation optical types: functionally significant variation in optical properties resulting from a combination of leaf traits, canopy structure, and phenology (Ustin and Gamon,
2010). This concept applies to remote sensing of biodiversity, but also provides a useful framework for analyzing the functional responses of different vegetation types, ecosystems, or biomes having different environmental limitations on fluxes. While full-spectral methods are often used, we illustrate the concept and its application with a focus on NDVI and PRI, largely because of their relevance to the LUE model and photosynthetic function.

One example of optical types emerges from the global biome mapping effort based on NDVI phenology (Defries and Townshend, 1994). At the ecosystem scale, using the light-response and LUE model framework (Fig. 3b), optical and flux measurements can be combined to distinguish optical types from environments having different resource levels associated with contrasting light-use efficiencies ( $\varepsilon$ values) (Huemmrich et al., 2011), providing a convenient basis for upscaling fluxes (Huemmrich et al., 2013). At the leaf or canopy level, there is a well-developed history of vegetation functional categories, based on concepts of adaptation and resource theory (Grime, 1977; Bloom et al., 1985; Wright et al., 2004). Sampling efforts can address categorical distinctions such as evergreens, annuals, or deciduous perennials (Gamon et al., 1997), or can be represented as a continuous spectrum of trait variation (Wright et al., 2004). In both cases, optical measurements can provide useful additional plant trait information regarding evolutionary responses or resource limitations at a range of scales. There is ample opportunity to further define this concept, to apply it to the flux tower footprint, and to use it to further clarify controls on surface-atmosphere fluxes of mass and energy and as a foundation for upscaling. Integrating optical sampling across the global flux tower network provides an ideal opportunity to further explore the optical type hypothesis.

In a recent review and meta-analysis of the PRI literature, Garbulsky et al. (2011) proposed that different ecosystems having contrasting constraints on carbon flux should also have contrasting optical properties reflected in PRI and NDVI dynamics. According to this hypothesis, the relationship between these optical indices and ecosystem carbon flux should vary across ecosystems, due to the contrasting environmental constraints and evolutionary responses to these constraints. Here, we restate this hypothesis to illustrate how NDVI and PRI signals might vary across functionally distinct vegetation types to yield complementary information on fluxes (Fig. 8). Accordingly, carbon fluxes in deciduous or annual vegetation (e.g., grasslands or most crops showing strong growth cycles) should be primarily driven by canopy structural changes, detectable via NDVI and related to LAI, $f_{\mathrm{APAR}}$, and other structural parameters strongly influencing ecosystem fluxes (Fig. 8a). The hypothesis predicts that these ecosystems would exhibit less variation associated with changing efficiency $(\varepsilon)$, detectable as PRI (Fig. 8c). On the other hand, evergreen vegetation with little seasonal variation in canopy structure should show a weak relationship between NDVI and carbon fluxes (Fig. 8b), but would show 

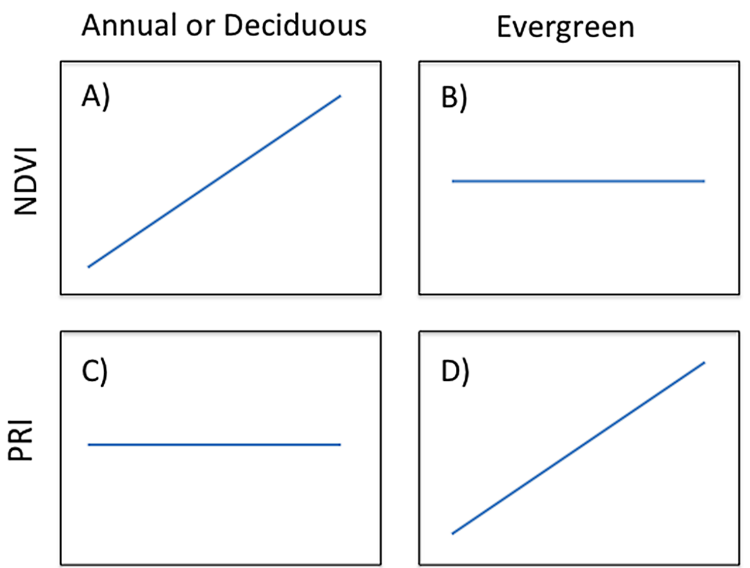

NEE or GEE

Figure 8. Hypothesized relationships between NDVI (a and b) and PRI (c and d) and daily NEE or GEE for annual or deciduous (left) or evergreen (right) vegetation. In this example, more positive values indicate greater photosynthetic carbon uptake. Modified from Garbulsky et al. (2011).

a strong correlation between PRI and fluxes (Fig. 8c), driven by the strong seasonal changes in chlorophyll : carotenoid ratios (Wong and Gamon, 2015a, b; Gamon et al., 2015).

This hypothesis of contrasting, complementary physiological and structural controls for different optical types has yet to be fully tested across a wide range of ecosystems and conditions, in part because the lack of standardized sampling protocols and appropriate databases have made it difficult to directly compare separate measurements from different studies, instruments, and ecosystems. Fully testing this complementarity hypothesis requires properly replicated instrumentation and experimental design, something that can best be achieved within the context of combined flux and optical networks. The benefit of this approach is that it can guide the application and inform the parameterization of the LUE model across contrasting ecosystems. In landscapes dominated by annual or deciduous vegetation, a good characterization of APAR via NDVI and irradiance measurements might be sufficient to define the annual course of gas exchange; in landscapes dominated by evergreens, the additional information on $\varepsilon$ becomes necessary, and sampling PRI could improve our understanding of flux controls and phenology (Wong and Gamon, 2015a, b). Adding standardized NDVI and PRI sensors to the flux tower network, and comparing ground measurements to satellite measurements, presents and ideal opportunity to test this hypothesis of complementary NDVI and PRI behavior associated with different vegetation types.

\section{The path forward}

In the past, remote sensing provided useful estimates of biophysical parameters and a powerful means of extrapolat- ing beyond the flux tower footprint. However, a newer crop of optical sampling methods has now emerged that allow deeper exploration of both physiological and structural controls on carbon fluxes. Two decades of proximal remote sensing within flux tower footprints have yielded many studies that relate optical signals to various components of ecosystem carbon fluxes. However, the literature largely remains a series of site-based observations, and we are still a long way from a comprehensive understanding of how best to integrate optical and flux measurements across biomes. Similarly, most analyses have been limited to one or a few vegetation indices, rather than exploring the full power of the electromagnetic spectrum, but improvements in instrumentation and data processing methods are now beginning to change that (Ustin et al., 2004; Serbin et al., 2012; Campbell et al., 2013). Comparative, experimental approaches are needed both within and across sites. The goal of this review has been to consider accomplishments so far, and to suggest directions and hypotheses for future work in the context of the global flux tower network.

Clearly, the LUE model provides a useful framework that is readily integrated with photosynthetic flux measurements, but we are left with several questions. Is there a single, consistent way to parameterize the LUE model from remote sensing, or does this model have to be calibrated individually for each ecosystem? Can the optical type concept be universally useful as a means of categorizing vegetation functional response and upscaling from sites to larger regions? Alternatively, are we better served by continuous-field approaches that interpret optical measurements in terms of continuous responses to environmental conditions and resource gradients? How do newly emerging SIF methods compare to other more established optical methods based on reflectance? Experimental, multi-scale, cross-site approaches are needed to more fully address these questions.

A full functional characterization of the flux tower footprint requires more than the LUE model, and continued comparisons with other approaches are also warranted. In addition to the optical sampling methods, other methods not fully discussed here, including thermal, lidar, microwave, and acoustic remote sensing, can add to our understanding of functional processes within the footprint. To obtain a deeper mechanistic understanding, the LUE approach can be compared to other, more biochemically based models of photosynthetic carbon flux (e.g., Sellers et al., 1992b, 1996; Serbin et al., 2012). Presumably, integration of several different and complementary optical methods (e.g., reflectance with fluorescence and canopy absorbance, including indices and fullspectral approaches) would provide a more complete assessment of ecosystem function than any single method alone (Fig. 5). Better integration of optical with structural (e.g., LIDAR) measurements, particularly using canopy radiative transfer models (e.g., van der Tol et al., 2009), would provide further insight into the structural vs. physiological controls on carbon flux, and could help explain emergent proper- 
ties. Integration of thermal sampling methods could help integrate energy balance and water vapor fluxes with the LUE approach (Anderson et al., 2008; Schull et al., 2015).

We need to expand our optical exploration of pigments beyond chlorophyll content and xanthophyll cycle pigment activity to include a wider range of plant pigments and their functional roles, with a particular focus on the rich world of carotenoid biochemistry and function. This should include the evaluation of carotenoid:chlorophyll pigment pools and novel pigment indices as a generalized stress response affecting isoprenoid emissions in addition to $\mathrm{CO}_{2}$ fluxes. Currently, our understanding of the role of carotenoids as optical indicators of stress responses is in its infancy, but is an area ripe for further exploration. As new instruments and platforms are developed, it is likely that new and improved pigment indices will also emerge.

To accomplish these goals, we need more systematic deployment of optical sensors with better attention to contextual information, as discussed above. Ideally, protocols would be sufficiently standardized or defined to allow ready comparisons across sites and studies. To match this deployment, we need a capable and flexible informatics approach that encompasses the large data volume represented by Fig. 2. This should accommodate not only flux and optical data, but also the essential ancillary data (e.g., pigment data or meteorological data) and metadata needed to fully interpret the optical and flux signals. Metadata systems that can fully capture the full context of optical measurements are needed. Such comprehensive data systems do not yet exist, but elements exist or are under development. Extending these existing databases and software tools to allow a more integrated analysis of complex data sets would be a good starting point.

Together, these approaches provide a richer understanding of mechanisms controlling fluxes of $\mathrm{CO}_{2}$ and other trace gases. Using the framework of the light response and LUE model, optical methods can help partition fluxes, provide additional methods of gap-filling, and facilitate upscaling methods based on the LUE model framework. The deeper understanding provided by integrating optical with flux sampling can also provide practical benefits, including improved assessment of ecosystem health, functional diversity, productivity, carbon sequestration, and surface-atmosphere feedbacks.

Acknowledgements. This perspective presented here was made possible by contributions by and discussions with many colleagues in the flux and optical sampling communities over the years, including many within the SpecNet, FLUXNET and EuroSpec communities. This work has been made possible by support from NSF, NASA, NSERC, CCSIP, CFI, iCORE/AITF, and the Rangeland Research Institute (University of Alberta).

Edited by: A. MacArthur

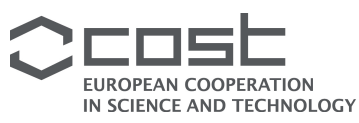

This publication was supported by COST - www.cost.eu

\section{References}

Anderson, M. C., Norman, J. M., Kustas, W. P., Houborg, R., Starks, P. J., and Agam, N.: A thermal-based remote sensing technique for routine mapping of land-surface carbon, water and energy fluxes from field to regional scales, Remote Sens. Environ., 112, 4227-4241, 2008.

Balzarolo, M., Anderson, K., Nichol, C., Rossini, M., Vescovo, L., Arriga, N., Wohlfahrt, G., Calvet, J.-C., Carrara, A., Cerasoli, S., Cogliati, S., Daumard, F., Eklundh, L., Elbers, J. A., Evrendilek, F., Handcock, R. N., Kaduk, J., Klumpp, K., Longdoz, B., Matteucci, G., Meroni, M., Montagnani, L., Ourcival., J.-M., Sánchez-Cañete, E. P., Pontailler, J.-V., Juszczak, R., Scholes, B., and Martín, M. P.: Ground-Based Optical Measurements at European Flux Sites: A Review of Methods, Instruments and Current Controversies, Sensors, 11, 7954-7981, 2011.

Barton, C. V. M. and North, P. R. J.: Remote sensing of canopy light use efficiency using the photochemical reflectance index Model and sensitivity analysis, Remote Sens. Environ., 78, 264273, 2001.

Björkman, O.: Physiological Plant Ecology, New Series, Physiological Plant Ecology I. Responses to the Physical Environment, edited by: Lange, O. L., Nobel, P. S., Osmond, C. B., and Ziegler, H., 12A, 57-107, 1981.

Björkman, O. and Demmig-Adams, B.: Regulation of photosynthetic light energy capture, conversion, and dissipation in leaves of higher plants, in: Ecophysiology of Photosynthesis, edited by: Schulze, E.-D., Caldwell, M. M., and Pospisilova, J., Springer, Berlin Heidelberg New York, 27-47,1994.

Bloom, A. J., Chapin, F. S., and Mooney, H. A.: Resource limitation in plants-an economic analogy, Annu. Rev. Ecol. Syst., 16, 363392, 1985.

Brugnoli, E. and Björkman, O.: Chloroplast movements in leaves - influence on chlorophyll fluorescence and measurements of light-induced absorbance changes related to $\Delta-\mathrm{pH}$ and zeaxanthin formation., Photosyn. Res., 32, 23-35, 1992.

Burba, G. and Anderson, D.: A brief practical guide to eddy covariance flux measurements: principles and workflow examples for scientific and industrial applications, LI-COR Biogeosciences, 2010.

Campbell, P. K. E., Middleton, E. M., Thome, K. J., Kokaly, R. F., Huemmrich, K. F., Lagomasino, D., Novick, K. A., and Brunsell, N. A.: EO-1 Hyperion reflectance time series at calibration and vaildation sites: stability and sensitivity to seasonal dynamics, IEEE J. Sel. Top. Appl. Earth Obs. Remote Sens., 6, 276-290, 2013.

Carter, G., Theisen, A., and Mitchell, R.: Chlorophyll fluorescence measured using the Fraunhofer line depth principle and relationship to photosynthetic rate in the field, Plant, Cell Environ., 13, 79-83, 1990.

Damm, A., Elbers, J., Erler, A., Gioli, B., Hamdi, K., Hutjes, R., Kosvancova, M., Meroni, M., Miglietta, F., Moersch, A., Moreno, J., Schickling, A., Sonnenschein, R., Udelhoven, T., van der Linden, S., Hostert, P., and Rascher, U.: Remote sensing of sun induced fluorescence to improve modeling of diurnal courses 
of gross primary production (GPP), Global Change Biol., 16, 171-186, 2010.

Defries, R. S. and Townshend, J. R. G.: NDVI-derived land cover classifications at a global-scale, Int. J. Remote Sens., 15, 35673586, 1994.

Demmig, B., Winter, K., Krüger, A., and Czygan, F.-C.: Photoinhibition and zeaxanthin formation in intact leaves - a possible role of the xanthophyll cycle in the dissipation of excess light energy, Plant Physiol., 84, 218-224, 1987.

Drolet, G. G., Middleton, E. M., Huemmrich, K. F., Hall, F. G., Amiro, B. D., Barr, A. G., Black, T. A., McCaughey, J. H., and Margolis, H. A.: Regional mapping of gross light-use efficiency using MODIS spectral indices, Remote Sens. Environ., 112, 3064-3078, 2008.

Eklundh, L., Jin, H., Schubert, P., Guzinski, R., and Heliasz, M.: An optical sensor network for vegetation phenology monitoring and satellite data calibration, Sensors, 11, 7678-7709, 2011.

Elias, B.: Pilotless drones: Background and considerations for Congress regarding unmanned aircraft operations in the national airspace system, Congressional Research Service, Library of Congress, 2012.

Frankenberg, C., Fisher, J. B., Worden, J., Badgley, G., Saatchi, S. S., Lee, J.-E., Toon, G. C., Butz, A., Jung, M., Kuze, A., and Yokota, T.: New global observations of the terrestrial carbon cycle from GOSAT: Patterns of plant fluorescence with gross primary productivity, Geophys. Res. Lett., 38, L17706, doi:10.1029/2011g1048738, 2011.

Gamon, J. A. and Berry, J. A.: Facultative and constitutive pigment effects on the Photochemical Reflectance Index (PRI) in sun and shade conifer needles, Isr. J. Plant Sci., 60, 85-95, 2012.

Gamon, J. A. and Bond, B.: Effects of irradiance and photosynthetic downregulation on the photochemical reflectance index in Douglas-fir and ponderosa pine, Remote Sens. Environ., 135, 141-149, 2013.

Gamon, J. A. and Surfus, J. S.: Assessing leaf pigment content and activity with a reflectometer, New Phytol., 143, 105-117, 1999.

Gamon, J. A., Field, C. B., Bilger, W., Björkman, O., Fredeen, A. L., and Peñuelas, J.: Remote-sensing of the xanthophyll cycle and chlorophyll fluorescence in sunflower leaves and canopies, Oecologia, 85, 1-7, 1990.

Gamon, J. A., Peñuelas, J., and Field, C. B.: A narrow-waveband spectral index that tracks diurnal changes in photosynthetic efficiency, Remote Sens. Environ., 41, 35-44, 1992.

Gamon, J. A., Field, C. B., Goulden, M. L., Griffin, K. L., Hartley, A. E., Joel, G., Peñuelas, J., and Valentini, R.: Relationships between NDVI, canopy structure, and photosynthesis in three Californian vegetation types, Ecol. Appl., 5, 28-41, 1995.

Gamon, J. A., Serrano, L., and Surfus, J. S.: The photochemical reflectance index: an optical indicator of photosynthetic radiation use efficiency across species, functional types, and nutrient levels, Oecologia, 112, 492-501, 1997.

Gamon, J. A., Field, C. B., Fredeen, A. L., and Thayer, S.: Assessing photosynthetic downregulation in sunflower stands with an optically-based model, Photosyn. Res., 67, 113-125, 2001.

Gamon, J. A., Kitajima, K., Mulkey, S. S., Serrano, L., and Wright, S. J.: Diverse optical and photosynthetic properties in a neotropical forest during the dry season: implications for remote estimation of photosynthesis, BioTropica, 37, 547-560, 2005.
Gamon, J. A., Cheng, Y. F., Claudio, H., MacKinney, L., and Sims, D. A.: A mobile tram system for systematic sampling of ecosystem optical properties, Remote Sens. Environ., 103, 246-254, $2006 a$.

Gamon, J. A., Rahman, A. F., Dungan, J. L., Schildhauer, M., and Huemmrich, K. F.: Spectral Network (SpecNet) - What is it and why do we need it?, Remote Sens. Environ., 103, 227-235, $2006 b$.

Gamon, J. A., Coburn, C., Flanagan, L. B., Huemmrich, K. F., Kiddle, C., Sanchez-Azofeifa, G. A., Thayer, D. R., Vescovo, L., Gianelle, D., Sims, D. A., Rahman, A. F., and Pastorello, G. Z.: SpecNet revisited: bridging flux and remote sensing communities, Can. J. Remote Sens., 36, S376-S390, 2010.

Gamon, J. A., Kovalchuck, O., Wong, C. Y. S., Harris, A., and Garrity, S. R.: Monitoring seasonal and diurnal changes in photosynthetic pigments with automated PRI and NDVI sensors, Biogeosciences, 12, 4149-4159, doi:10.5194/bg-12-4149-2015, 2015.

Garbulsky, M. F., Peñuelas, J., Papale, D., Ardö, J., Goulden, M. L., Kiely, G., Richardson, A. D., Rotenberg, E., Veenendaal, E. M., and Filella, I.: Patterns and controls of the variability of radiation use efficiency and primary productivity across terrestrial ecosystems, Global Ecol. Biogeogr., 19, 253-267, 2010.

Garbulsky, M. F., Peñuelas, J., Gamon, J., Inoue, Y., and Filella, I.: The photochemical reflectance index (PRI) and the remote sensing of leaf, canopy and ecosystem radiation use efficiencies: A review and meta-analysis, Remote Sens. Environ., 115, 281-297, 2011.

Garrity, S. R., Eitel, J. U. H., and Vierling, L. A.: Disentangling the relationships between plant pigments and the photochemical reflectance index reveals a new approach for remote estimation of carotenoid content, Remote Sens. Environ., 115, 628-635, 2011.

Gitelson, A. A. and Gamon, J. A.: The need for a common basis for defining light-use efficiency: Implications for productivity estimation, Remote Sens. Environ., 156, 196-201, 2015.

Goerner, A., Reichstein, M., and Rambal, S.: Tracking the seasonal drought effects on ecosystem light use efficiency with satellitebased PRI in a Mediterranean forest, Remote Sens. Environ., 113, 1101-1111, 2009.

Goulden, M. L., Daube, B. C., Fan, S.-M., Sutton, D. J., Bazzaz, A., Munger, J. W., and Wofsy, S. C.: Physiological responses of a black spruce forest to weather, J. Geophys. Res.-Atmos., 102, 28987-28996, 1997.

Goward, S. N., Tucker, C. J., and Dye, D. G.: North-American vegetation patterns observed with the NOAA-7 Advanced Very High Resolution Radiometer, Vegetatio, 64, 3-14, 1985.

Grime, J. P.: Evidence for the existence of three primary strategies in plants and its relevance to ecological and evolutionary theory, Am. Nat., 111, 1169-1194, 1977.

Guarini, R., Nichol, C., Clement, R., Loizzo, R., Grace, J., and Borghetti, M.: The utility of MODIS-sPRI for investigating the photosynthetic light-use efficiency in a Mediterranean deciduous forest, Int. J. Remote Sens., 35, 6157-6172, 2014.

Hall, F. G., Huemmrich, K. F., Goetz, S. J., Sellers P. J., and Nickeson, J. E.: Satellite remote sensing of surface energy balance: success, failures, and unresolved issues in FIFE, J. Geophys. Res., 97, 19061-19089, 1992.

Harris, A., Gamon, J., Pastorello, G., and Wong, C.: Retrieval of the photochemical reflectance index for assessing xanthophyll cycle 
activity: a comparison of near-surface optical sensors, Biogeosciences, 11, 6277-6292, doi:10.5194/bg-11-6277-2014, 2014.

Heinsch, F. A., Zhao, M., Running, S. W., Kimball, J. S., Nemani, R. R., Davis, K. J., Bolstad, P. V., Cook, B. D., Desai, A. R., Ricciuto, D. M., Law, B. E., Oechel, W. C., Kwon, H., Luo, H., Wofsy, S. C., Dunn, A. L., Munger, J. W., Baldocchi, D. D., Xu, L., Hollinger, D. Y., Richardson, A. D., Stoy, P. C., Siqueira, M. B. S., Monson, R. K., Burns, S. P., and Flanagan, L. B.: Evaluation of remote sensing based terrestrial productivity from MODIS using regional tower eddy flux network observations, IEEE Trans. Geosci. Remote Sens., 44, 1908-1925, 2006.

Hilker, T., Coops, N. C., Nesic, Z., Wulder, M. A., and Black, A. T.: Instrumentation and approach for unattended year round tower based measurements of spectral reflectance, Comput. Electron. Agr., 56, 72-84, 2007.

Hilker, T., Coops, N. C., Hall, F. G., Black, T. A., Wulder, M. A., Nesic, Z., and Krishnan, P.: Separating physiologically and directionally induced changes in PRI using BRDF models, Remote Sens. Environ., 112, 2777-2788, 2008.

Hilker, T., Hall, F. G., Coops, N. C., Lyapustin, A., Wang, Y., Nesic, Z., Grant, N., Black, T. A., Wulder, M. A., Kljun, N., Hopkinson, C., and Chasmer, L.: Remote sensing of photosynthetic light-use efficiency across two forested biomes: Spatial scaling, Remote Sens. Environ., 114, 2863-2874, 2010.

Hilker, T., Gitelson, A., Coops, N. C., Hall, F. G., and Black, T. A.: Tracking plant physiological properties from multi-angular tower-based remote sensing, Oecologia, 165, 865-876, 2011.

Huemmrich, K. F., Black, T. A., Jarvis, P. G., McCaughey, J. H., and Hall, F. G.: High temporal resolution NDVI phenology from micrometeorological radiation sensors, J. Geophys. Res.-Atmos., 104, 27935-27944, 1999.

Huemmrich, K. F., Gamon, J. A., Tweedie, C. E., Oberbauer, S. F., Kinoshita, G., Houston, S., Kuchy, A., Hollister, R. D., Kwon, H., Mano, M., Harazono, Y., Webber, P. J., and Oechel, W. C.: Remote sensing of tundra gross ecosystem productivity and light use efficiency under varying temperature and moisture conditions, Remote Sens. Environ., 114, 481-489, 2010.

Huemmrich, K. F., Gamon, J. A., Tweedie, C. E., Campbell, P. K. E., Landis, D. R., and Middleton, E. M.: Arctic tundra vegetation functional types based on photosynthetic physiology and optical properties, IEEE J. Sel. Top. Appl. Earth Obs. Remote Sens., 6, 265-275, 2013.

Joiner, J., Yoshida, Y., Vasilkov, A. P., Yoshida, Y., Corp, L. A., and Middleton, E. M.: First observations of global and seasonal terrestrial chlorophyll fluorescence from space, Biogeosciences, 8, 637-651, doi:10.5194/bg-8-637-2011, 2011.

Joiner, J., Yoshida, Y., Vasilkov, A. P., Schaefer, K., Jung, M., Guanter, L., Zhang, Y., Garrity, S., Middleton, E. M., Huemmrich, K. F., Gu, L., and Belelli-Marchesini, L.: The seasonal cycle of satellite chlorophyll fluorescence observations and its relationship to vegetation phenology and ecosystem atmosphere carbon exchange, Remote Sens. Environ., 152, 375-391, 2014.

Jones, H. G.: Plants and Microclimate: a Quantitative Approach to Environmental Plant Physiology, Cambridge University Press, 2013.

Knohl, A. and Baldocchi, D. D.: Effects of diffuse radiation on canopy gas exchange processes in a forest ecosystem, J. Geophys. Res.-Biogeo., 113, G02023, doi:10.1029/2007jg000663, 2008.
Kumar, M. and Monteith, J. L.: Remote sensing of plant growth, in: Plants and the Daylight Spectrum, edited by: Smith, H., Academic Press, London, 133-144, 1981.

Long, S. P. and Bernacchi, C. J.: Gas exchange measurements, what can they tell us about the underlying limitations to photosynthesis? Procedures and sources of error, J. Exp. Bot., 54, 2393-2401, doi:10.1093/jxb/erg262, 2003.

Meroni, M., Rossini, M., Guanter, L., Alonso, L., Rascher, U., Colombo, R., and Moreno, J.: Remote sensing of solar-induced chlorophyll fluorescence: Review of methods and applications, Remote Sens. Environ., 113, 2037-2051, 2009.

Michaletz, S. T., Cheng, D., Kerkhoff, A. J., and Enquist, B. J.: Convergence of terrestrial plant production across global climate gradients, Nature, 512, 39-43, 2014.

Middleton, E. M., Cheng, Y.-B., Hilker, T., Black, T. A., Krishnan, P., Coops, N. C., and Huemmrich, K. F.: Linking foliage spectral responses to canopy-level ecosystem photosynthetic light-use efficiency at a Douglas-fir forest in Canada, Can. J. Remote Sens., 35, 166-188, 2009.

Monteith, J. L.: Climate and efficiency of crop production in Britain, Philos. T. Roy. Soc. B, 281, 277-294, 1977.

Norman, J. M. and Arkebauer, T. J.: Predicting canopy light-use efficiency from leaf characteristics, Chapter 5, in: Modeling Crop Photosynthesis - from Biochemistry to Canopy, edited by: Boote, K. J. and Loomis, R. S., CCSA Special Publication, 19, 75-94, 1991.

Osmond, C. B. and Chow, W. S.: Ecology of photosynthesis in the sun and shade - summary and prognostications, Aust. J. Plant Physiol., 15, 1-9, 1988.

Peng, Y., Gitelson, A. A., Keydan, G., Rundquist, D. C., and Moses, W.: Remote estimation of gross primary production in maize and support for a new paradigm based on total crop chlorophyll content, Remote Sens. Environ., 115, 978-989, 2011.

Peñuelas, J., Filella, I., and Gamon, J. A.: Assessment of photosynthetic radiation-use efficiency with spectral reflectance, New Phytol., 131, 291-296, 1995.

Peñuelas, J., Marino, G., Llusia, J., Morfopoulos, C., FarréArmengol, G., and Filella, I.: Photochemical reflectance index as an indirect estimator of foliar isoprenoid emissions at the ecosystem level, Nat. Communicat., 4, 2604, doi:10.1038/ncomms3604, 2013.

Porcar-Castell, A., Tyystjärvi, E., Atherton, J., van der Tol, C., Flexas, J., Pfündel, E. E., Moreno, J., Frankenberg, C., and Berry, J. A.: Linking chlorophyll a fluorescence to photosynthesis for remote sensing applications: mechanisms and challenges, J. Exp. Bot., 65, 4065-4095, 2014.

Reichstein, M., Stoy, P. C., and Desai, A. R.: Partitioning of net fluxes, in: Eddy Covariance: A Practical Guide to Measurement and Data, edited by: Aubinet, M., Vesala, T., and Papale, D., Springer, Dordrecht, 263-289, 2012.

Richardson, A. D., Braswell, B. H., Hollinger, D. Y., Jenkins, J. P., and Ollinger, S. V.: Near-surface remote sensing of spatial and temporal variation in canopy phenology, Ecol. Appl., 19, 14171428, 2009.

Ruimy, A., Saugier, B., and Dedieu, G.: Methodology for the estimation of terrestrial net primary production from remotely sensed data, J. Geophys. Res.-Atmos., 99, 5263-5283, 1994.

Running, S. W., Nemani, R. R., Heinsch, F. A., Zhao, M. S., Reeves, M., and Hashimoto, H.: A continuous satellite-derived measure 
of global terrestrial primary production, BioScience, 54, 547560, 2004.

Schull, M. A., Anderson, M. C., Houborg, R., Gitelson, A., and Kustas, W.P.: Thermal-based modeling of coupled carbon, water and energy fluxes using nominal light use efficiencies constrained by leaf chlorophyll observations, Biogeosciences, 12, 1511-1523, doi:10.5194/bg-12-1511-2015, 2015.

Sellers, P. J.: Canopy reflectance, photosynthesis, and transpiration, II. The role of biophysics in the linearity of their interdependence, Remote Sens. Environ., 21, 143-183, 1987.

Sellers, P. J., Berry, J. A., Collatz, G. J., Field, C. B., and Hall, F. G.: Canopy reflectance, photosynthesis, and transpiration, III. A reanalysis using improved leaf models and a new canopy integration scheme, Remote Sens. Environ., 42, 187-216, 1992a.

Sellers, P. J., Hall, F. G., Asrar, G., Strebel, D. E., and Murphy, R. E.: An overview of the First International Satellite Land Surface Climatology Project (ISLSCP) Field Experiment (FIFE), J. Geophys. Res., 97, 18345-18371, 1992 b.

Sellers, P. J., Bounoua, L., Collatz, G. J., Randall, D. A., Dazlich, D. A., Los, S. O., Berry, J. A., Fung, I., Tucker, C. J., Field, C. B., and Jensen, T. G.: Comparison of radiative and physiological effects of doubled atmospheric $\mathrm{CO}_{2}$ on climate, Science, 271, 1402-1406, 1996.

Sellers, P. J., Hall, F. G., Kelly, R. D., Black, A., Baldocchi, D., Berry, J., Ryan, M., Ranson, K. J., Crill, P. M., Lettenmaier, D. P., Margolis, H., Cihlar, J., Newcomer, J., Fitzjarrald, D., Jarvis, P. G., Gower, S. T., Halliwell, D., Williams, D., Goodison, B., Wickland, D. E., and Guertin, F. E.: BOREAS in 1997: Experiment overview, scientific results, and future directions, J. Geophys. Res.-Atmos, 102, 28731-28769, 1997.

Serbin, S. P., Dillaway, D. N., Kruger, E. L., and Townsend, P. A.: Leaf optical properties reflect variation in photosynthetic metabolism and its sensitivity to temperature, J. Exp. Bot., 63, 489-502, 2012.

Sims, D. A. and Gamon, J. A.: Relationships between leaf pigment content and spectral reflectance across a wide range of species, leaf structures and developmental stages, Remote Sens. Environ., 81, 337-354, 2002.

Sims, D. A. and Gamon, J. A.: Estimation of vegetation water content and photosynthetic tissue area from spectral reflectance: a comparison of indices based on liquid water and chlorophyll absorption features, Remote Sens. Environ., 84, 526-537, 2003.

Sims, D. A., Luo, H. Y., Hastings, S., Oechel, W. C., Rahman, A. F., and Gamon, J. A.: Parallel adjustments in vegetation greenness and ecosystem $\mathrm{CO}_{2}$ exchange in response to drought in a Southern California chaparral ecosystem, Remote Sens. Environ., 103, 289-303, 2006.

Soudani, K., Hmimina, G., Dufrêne, E., Berveiller, D., Delpierre, N., Ourcival, J.-M., Rambal, S., and Joffre, R.: Relationships between photochemical reflectance index and light-use efficiency in deciduous and evergreen broadleaf forests, Remote Sens. Environ., 144, 73-84, 2014.
Tucker, C. J., Townshend, J. R. G., and Goff, T. E.: African landcover classification using satellite data, Science, 227, 369-375, 1985.

Ustin, S. L. and Gamon, J. A.: Remote sensing of plant functional types, New Phytol., 186, 795-816, 2010.

Ustin, S. L., Roberts, D. A., Gamon, J. A., Asner, G. P., and Green, R. O.: Using imaging spectroscopy to study ecosystem processes and properties, BioScience, 54, 523-534, 2004.

Ustin, S. L., Gitelson, A. A., Jacquemoud, S., Schaepman, M. E., Asner, G. P., Gamon, J. A., and Zarco-Tejada, P.: Retrieval of foliar information about plant pigment systems from high resolution spectroscopy, Remote Sens. Environ. 113, 67-77, 2009.

van der Tol, C., Verhoef, W., Timmermans, J., Verhoef, A., and Su, Z., An integrated model of soil-canopy spectral radiances, photosynthesis, fluorescence, temperature and energy balance, Biogeosciences, 6, 3109-3129, doi:10.5194/bg-6-3109-2009, 2009.

van der Tol, C., Berry, J. A., Campbell, P. K. E., and Rascher, U.: Models of fluorescence and photosynthesis for interpreting measurements of solar-induced chlorophyll fluorescence. J. Geophys. Res.-Biogeoscience, 119, 2312-2327, 2014.

Vesala, T., Kljun, N., Rannik, Ü., Rinne, J., Sogachev, A., Markkanen, T., Sabelfeld, K., Foken, Th., and Leclerc, M. Y.: Flux and concentration footprint modelling: State of the art, Environ. Pollut., 152, 653-666, 2008.

von Caemmerer, S. and Farquhar, G. D.: Some relationships between the biochemistry of photosynthesis and the gas-exchange of leaves, Planta, 153, 376-387, 1981.

Wofsy, S. C., Goulden, M. L., Munger, J. W., Fan, S. M., Bakwin, P. S., Daube, B. C., Bassow, S. L., and Bazzaz, F. A.: Net exchange of $\mathrm{CO}_{2}$ in a midlatitude forest, Science, 260, 1314-1317, 1993.

Wong, C. Y. S. and Gamon, J. A.: Three causes of variation in the photochemical reflectance index (PRI) in evergreen conifers, New Phytol., 206, 187-195, 2015a.

Wong, C. Y. S. and Gamon, J. A.: The photochemical reflectance index provides an optical indicator of spring photosynthetic activation in evergreen conifers, New Phytol., 206, 196-208, 2015b.

Wright, I. J., Reich, P. B., Westoby, M., Ackerly, D. D., Baruch, Z., Bongers, F., Cavender-Bares, J., Chapin, T., Cornelissen, J. H. C., Diemer, M., Flexas, J., Garnier, E., Groom, P. K., Gulias, J., Hikosaka, K., Lamont, B. B., Lee, T., Lee, W., Lusk, C., Midgley, J. J., Navas, M.-L., Niinemets, Ü., Oleksyn, J., Osada, N., Poorter, H., Poot, P., Prior, L., Pyankov, V. I., Roumet, C., Thomas, S. C., Tjoelker, M. G., Veneklaas, E. J., and Villar, R.: The worldwide leaf economics spectrum, Nature, 428, 821-827, 2004.

Zhang, L.-X., Zhou, D.-C., Fan, J.-W., and Hu, Z.-M.: Comparison of four light use efficiency models for estimating terrestrial gross primary production, Ecol. Model., 300, 30-39, 2015.

Zygielbaum, A. I., Arkebauer, T. J., Walter-Shea, E. A., and Scoby, D. L.: Detection and measurement of vegetation photoprotection stress response using PAR reflectance, Isr. J. Plant Sci., 60, 37 47, 2012. 